Aus Dr. R. Ledermanns Serodiagnostischem Laboratorium in Berlin.

\section{Ueber die praktische Verwertbarkeit des von v. Wassermann kontrollierten Lues- extraktes.}

Von Henny Stern, wissenschaftlicher Hilfsarbeiterin.

Unter den für die Anstellung der Wassermannschen Reaktion notwendigen Reagentien stößt die Beschaffung des Antigens für viele Untersucher am meisten auf Schwierigkeiten. Zwar gibt es jetzt im Handel käuflich eine Reihe wohl brauchbarer Extrakte. Da diese aber fast alle aus normalen Organen, entweder aus Menschen- oder Meerschweinchenherzen hergestellt sind, so erfüllen sie nicht die von dem Erfinder der Reaktion aufgestellte Forderung, da $\mathrm{B}$ man bei der Anstellung der Reaktion zur Erzielung eines einwandfreien Resultats mindestens einen aus syphilitischer Fötalleber hergestellten Extrakt verwenden solle.

v. Wassermann selbst ist von seiner ursprünglichen Forderung, nur wäßrige Extraktc aus syphilitischer Fötalleber als Antigen zu benutzen, wegen ihrer relativ leichten Zersetzbarkeit in neuerer Zeit abgegangen, nachdem er sich überzeugt hatte, daß auch die alkoholischen Extrakte, deren Haltbarkeit eine wesentlich längere, wenn auch nicht unbegrenzbar lange ist, gute und sichere Resultate ergeben. Mit diesem Zugeständnis der Gleichwertigkeit der alkoholischen mit den wäßrigen Fötalleberextrakten war aber zugleich die Möglichkeit gegeben, diese alkoholischen Extrakte in größerer Menge herzustellen und im Handel erscheinen zu lassen. v. Wassermann glaubte aber auch dadurch die Anstellung der Reaktion für diejenigen Laboratorien, die sich nicht an den großen Zentren der wissenschaftlichen Institute oder Krankenhäuser befinden, zu erleichtern, indem er zugleich die andern Reagentien wie den Ambozeptor, das Hammelblut und die Kontrollsera weiteren Kreisen zugänglich machte.

Nur das Komplement, das ja überall leicht zu beschaffen ist, wurde nicht in den Kreis der käuflich abzugebenden Reagentien aufgenommen, da seine Haltbarkeit sich nur über wenige Tage erstreckt. Die Darstellung und Abgabe der Reagentien wurde der Firma Ludwig Wilhelm Gans in Frankfurt a. M. übergeben, während v. Wassermann in Gemeinschaft mit G. Meier sich nur die Kontrolle über die Brauchbarkeit der Reagentien vorbehielt. Durch die Freundlichkeit der genannten Firma wurde unserem Laboratorium ein größeres Versuchsquantum dieser käuflichen Reagentien zur Verfügung gestellt, und so sind wir imstande gewesen, in 102 Fällen die Wirksamkeit des Extraktes mit den von uns selbst hergestellten teils wäßrigen, teils alkoholischen Antigenen aus syphilitischen Fötallebern zu vergleichen.

Die ersten Sendungen der Extrakte, welchen noch gewisse technische Mängel bei der Konservierung anhafteten, wurden von der Fabrik kurz nach dem Erscheinen zurückgezogen, nachdem auch wir die gleiche Beobachtung bei der Anstellung unserer vergleichenden Versuche gemacht hatten. Die seitdem uns von der Fabrik gelieferten Extrakte haben dagegen vollkommen gleiche Resultate mit unsern eigenen Extrakten ergeben.

Von den 102 untersuchten Sera, welche zum größten Teil unserer Klinik und Poliklinik, ferner dem Poliklinischen Institut für innere Krankheiten des Herrn Geh.-Rat Goldscheider, der Nerven-Poliklinik des Herrn Prof. Oppenheim, sowie andern wissenschaftlichen Instituten entstammten, war uns bisher nur in 82 Fällen die Diagnose zugänglich. In 62 Fällen konnte entweder durch klinische Untersuchung oder durch ${ }_{2}^{\mathbb{T}}$ die Anamnese Lues festgestellt werden, in 37 davon wurde in allen Extrakten gleichmäßig eine starke Reaktion, in ${ }^{r a c h t}$ Fällen eine schwache Reaktion festgestellt.

Unter den Sera mit schwacher Reaktion befanden sich drei von Kranken nach Salvarsaninjektionen. In 16 Fällen mit Lues in der Anamnese war die Reaktion sowohl mit dem Wassermannschen als auch mit unseren eigenen Extrakten negativ. Es handelte sich dabei meist um Kranke im latenten Stadium, ferner um solche nach Quecksilber- und Salvarsan- injektionen, schließlich auch um Kranke, die man sonst nach ärztlichem Ermessen hätte als geheilt betrachten können. In einem Falle, in dem die Diagnose Lues sicher war, ergab der Wassermannsche Extrakt ein schwach positives Resultat, während unsere Extrakte eine Hemmung nicht mehr erkennen ließen. In 20 Fällen wurde bei nichtsyphilitischen Erkrankungen mit allen Extrakten gleichmäßig ein negatives Resultat erzielt. Darunter waren elf, welche zu differentialdiagnostischen Zwecken der serologischen Untersuchung zugewiesen waren.

Unter sämtlichen 102 Sera fanden sich 38 mit starker, 8 mit schwacher, 55 mit negativer Reaktion, ferner das bereits erwähnte, von uns als negativ, mit dem Wassermannschen Extrakt als positiv befundene Serum.

Der Wasser mannsche Extrakt wurde der Vorschrift gemäß in der Einzeldosis von $0,09 \mathrm{zum}$ Versuch verwendet. Dabei machten wir die Beobachtung, daß er bei mehreren Sendungen in der doppelten Dosis mit $\mathrm{NaCl}$ eine mehr oder weniger starke Hemmung ergab, ohne daß jedoch dadurch die Richtigkeit der Resultate der Serumuntersuchung beeinträchtigt wurde. Bei der letzten Sendung des Extrakts, welches gleichfalls vollständig übereinstimmende Resultate mit dem unseren erzielte, konnten wir die Alleinhemmung des Extrakts in doppelter Dosis nicht mehr beobachten.

Der an Fließpapier angetrocknete Ambozeptor hat sich längere Zeit hindurch haltbar erwiesen und ist in der vorgeschriebenen Bearbeitung stets brauchbar gewesen.

Ebenfalls ist das nach einem bestimmten, uns unbekannten Verfahren präparierte Hammelblut stets unzersetzt geblieben und hat sich bei Aufbewahrung im Eisschrank über drei Wochen lang gehalten.

Weniger praktisch erscheint uns die Beigabe von Kontrollsera, da diese sich sehr schnell zersetzen und dadurch leicht zu Irrtümern führen können.

Wir empfehlen daher, diese nicht mehr käuflich abzugeben, zumal die Beschaffung von frischen Kontrollsera wohl nirgends auf besondere Schwierigkeiten stoßen dürfte.

Zusammenfassung. Der jetzt von der Firma Lud wig Wilhelm Gans herausgegebene alkoholische Extrakt aus syphilitischen Fötallebern arbeitet in tadelloser Weise und bildet daher in Gemeinschaft mit dem gleichzeitig erhältlichen Ambozeptor und Hammelblut eine wertvolle Erleichterung für viele Untersucher, namentlich für solche, welche nicht täglich Reaktionen anstcllen und nicht in der Iage sind, sich ihre Reagentien selbst darzl stellen. In Betracht zu ziehen wäre es, den Gebrauchstiter des Extrakts (jetzt 0,09) etwas niedriger einzustellen, namentlich in einer Dosis, welche mit der doppelten Kochsalzmenge keine starke Hemmung gibt. Wir haben ja bisher - gerade auf A. von Wassermanns und G. Meiers Empfehlung - die sogenannte Extraktkontrolle als ein wertvolles Postvlat bei der Anstellung der Reaktion angesehen, und viele Untersucher möchten ungern darauf verzichten. In der Tat haben wir auch bei Verwendung von Einzeldosen von 0,08 und 0,07 vollkommen brauchbare Resultate erhalten und dadurch die Eigenhemmung des Fxtraktes wesentlich reduzieren können. 